\title{
A TRADUÇÃO DE DOIS SÍTIOS ELETRÔNICOS DA UNIVERSIDADE FEDERAL DE UBERLÂNDIA SOB O VIÉS DA INTERNACIONALIZAÇÃO
}

\author{
THE TRANSLATION OF TWO WEBSITES IN UNIVERSIDADE FEDERAL DE \\ UBERLÂNDIA FROM THE PERSPECTIVE OF INTERNATIONALIZATION
}

\author{
Helda Maria Falcão de GOIS \\ Pesquisadora autônoma \\ Uberlândia, Minas Gerais, Brasil \\ orcid.org/0000-0002-3919-1268 \\ heldafgois@hotmail.com
}

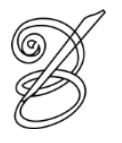

\author{
Igor Antônio Lourenço DA SILVA \\ Universidade Federal de Uberlândia, Instituto de Letras e \\ Linguística, Bacharelado em Tradução \\ Uberlândia, Minas Gerais, Brasil \\ orcid.org/0000-0003-0738-3262 \\ ials@ufu.br
}

Resumo: Este artigo, voltado para o processo de internacionalização da Universidade Federal de Uberlândia (UFU), investiga dois sítios eletrônicos dos seus programas de pós-graduação (PPG), ambos com versões em língua inglesa. A análise da tradução dos sítios de ambos os programas revela problemas de ordem linguística, cultural e tradutória, havendo a necessidade de revisão e tradução de diversos conteúdos, bem como de reconfiguração de alguns detalhes visuais. Na tentativa de promover reflexão sobre um dos aspectos da internacionalização do ensino superior no Brasil, qual seja a internacionalização dos seus sítios eletrônicos, são feitas algumas propostas de reformulações e considerações que ensejam uma reflexão sobre a internacionalização de sítios eletrônicos universitários e a sua interface com os Estudos da Tradução.

Palavras-chave: Sítios eletrônicos. Tradução. Internacionalização. Universidade Federal de Uberlândia. Pósgraduação.

Abstract: This article is oriented to the internationalization process at Universidade Federal de Uberlandia $(U F U)$ and investigates two websites of graduate programs, both with English language versions. The analysis of the website translations reveals problems of linguistic, cultural and translational nature, which urge the revision and translation of several contents, as well as redesign of some visual aspects. To promote a reflection on one of the aspects of the internationalization of higher education in Brazil, namely the internationalization of its electronic websites, some proposals are made for reformulations, and considerations are put forward aiming at a reflection on the internationalization of university websites and its interface with the Translation Studies.

Keywords: Websites. Translation. Internationalization. Universidade Federal de Uberlandia. Graduate program. 


\section{Introdução}

om a intenção de se promoverem e de atraírem alunos, professores e pesquisadores
estrangeiros, as instituições de ensino superior viram-se obrigadas a internacionalizar-
se, apostando em parcerias com instituições de outros países. Em outras palavras, essas instituições identificaram a necessidade crescente de traduzir seus materiais promocionais para que fosse possível sua inclusão no mundo globalizado (RAMOS, 2015).

Para a CAPES (Coordenação de Aperfeiçoamento de Pessoal de Nível Superior), a internacionalização das Instituições de Ensino Superior (IES) tem a função de transformar a vida universitária, responsabilizando-se pela troca de conhecimentos acadêmicos e permitindo a construção de capacidades sociais e econômicas. Trata-se de um processo dinâmico e amplo que envolve o ensino, a pesquisa e as trocas entre a universidade e a sociedade, constituindo "um recurso para tornar a educação superior responsiva aos requisitos e desafios de uma sociedade globalizada. É o estágio mais elevado das relações internacionais entre as universidades" (CAPES, 2017, p. 6).

Boa parte dos sítios eletrônicos das instituições de ensino superior já está sendo 76 traduzida para várias outras línguas, sobretudo no que diz respeito aos programas de pósgraduação (PPG). Neste contexto, este artigo investiga a tradução dos sítios eletrônicos de dois programas de pós-graduação da Universidade Federal de Uberlândia (PPGCSA - Programa de Pós-Graduação em Ciências da Saúde e PPGECO - Programa de Ecologia e Conservação de Recursos Naturais) sob a perspectiva da internacionalização e avalia se esses sítios eletrônicos se configuram, conforme Fernández-Costales (2010), como materiais promocionais, informacionais ou comunicativos;

\section{A Universidade, a Globalização e a Internacionalização}

Fernandez (2011) discorre sobre a universidade como local de produção e divulgação de conhecimento científico. Para tal, ressalta:

\footnotetext{
[a] universidade é uma instituição de educação superior, pensada como lugar de produção e divulgação do conhecimento científico, [...] centrada no ensino e na formação de profissionais, mas que também se desdobra na prestação de serviços e na troca de conhecimento com a sociedade. (FERNANDEZ, 2011, p. 14)
}

Outra definição sobre o papel da universidade pode ser observada a seguir: 
[...] lugar privilegiado para conhecer a cultura universal e as várias ciências, para criar e divulgar o saber; mas deve buscar uma identidade própria e uma adequação à realidade nacional. Suas finalidades são o ensino, a pesquisa e a extensão. Ela é a instituição social que forma, de maneira sistemática e organizada, os profissionais técnicos e intelectuais de nível superior que as sociedades necessitam. (KUNSCH, 1992, p. 18 apud FERNANDEZ, 2011 p. 15)

Fernandez (2011) considera a universidade como uma organização que forma profissionais e troca com o mundo globalizado conhecimentos e tecnologias nela produzidos. Essas trocas de conhecimentos são inevitáveis e, no mundo globalizado em que as universidades estão inseridas, elas se processam diariamente, seja através de cursos de extensão, de seminários internacionais de pesquisas científicas, de seus sítios eletrônicos ou de atividades que envolvam relações internacionais.

Ramos (2015, p. ii) afirma que "a comunicação institucional é uma das grandes preocupações do ensino superior", uma vez que seu objetivo é captar alunos e públicos diversificados nos níveis nacional e internacional. As instituições necessitam recorrer cada vez mais à tradução de seus materiais com o objetivo de atrair estudantes estrangeiros.

A internacionalização das Instituições de Ensino Superior (IES) brasileiras tem sido, nos últimos anos, tema recorrente no âmbito das discussões sobre educação superior. Entretanto, "não existe [sic] documentos do governo brasileiro que explorem, de forma mais clara, a internacionalização da educação superior e que tratem a mesma [sic] como política pública” (MIRANDA; STALLIVIERI, 2017, p. 590).

Ainda nessa linha de considerações, a pesquisa realizada pela CAPES (2017) em relação aos sítios eletrônicos das IES brasileiras apontou que nem metade dos sítios eletrônicos dos PPG possui uma versão em outro idioma. Mesmo com o fim do programa Ciência sem Fronteiras (CsF), os projetos de colaboração e os programas no exterior têm alavancado cada vez mais a quantidade de estudantes estrangeiros vindo estudar no Brasil e cada vez mais professores e pesquisadores brasileiros indo ao exterior para estudar e discutir resultados com parceiros estrangeiros.

\section{Tradução, Localização e Internacionalização}

Mesquita (2015, p. 10) aponta que "a localização e a internacionalização de sites são práticas que visam, dentre outros objetivos, (i) atingir ou atrair clientes em/de novos mercados; e/ou (ii) conferir maior credibilidade e visibilidade à instituição, empresa ou produto" a que seu conteúdo se destina. Fernández-Costales (2010) afirma ser importante investigar se, ao se 
internacionalizarem os sítios eletrônicos universitários, estes passam do 'global para o local', como ocorre no mercado da localização, ou se passam do 'local para o global'.

Fernández-Costales (2010) define localização como a "adaptação de um produto de maneira íntegra a uma cultura de destino, ou localidade, ajustando-se plenamente aos parâmetros culturais daquele país-alvo" ${ }^{1 "}$ (p. 504), devendo ser entendida como parte integrante de um conjunto definido pelo acrónimo GILT: Globalização, "Internacionalização", Localização e Tradução, representado na Figura 1.

O termo "internacionalização" é aqui grafado entre aspas para indicar que não coincide com o conceito de internacionalização citado anteriormente.

Figura 1 - Diagrama GILT

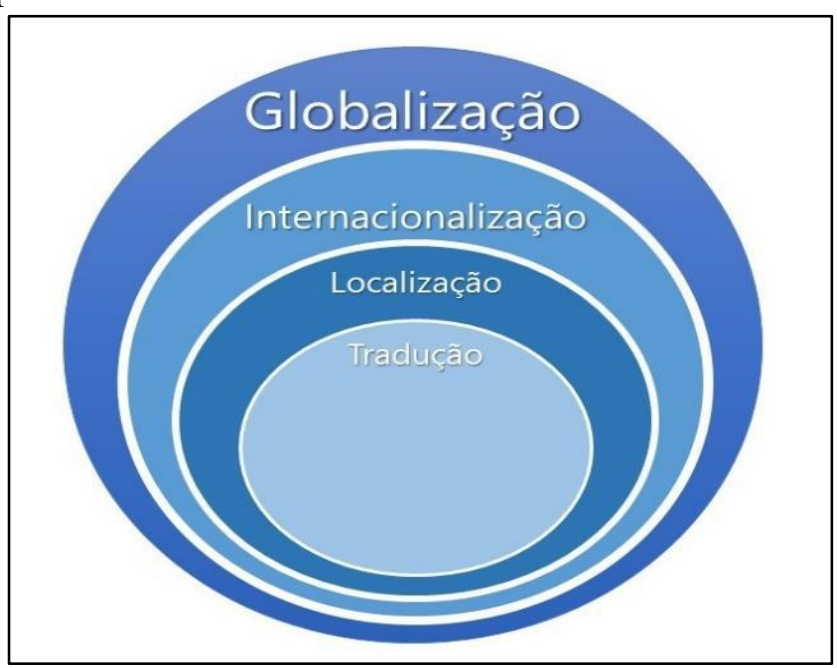

Fonte: RAMOS, 2015, p. 35.

Retomando alguns conceitos e preceitos adotados no âmbito dos estudos da localização, que têm por objeto os sítios eletrônicos e softwares, tem-se o seguinte:

- globalização "se refere às atividades comerciais relacionadas à venda de um produto ou serviço em vários mercados regionais"”2 (SANDRINI, 2008, p. 1);

- internacionalização “descreve o processo de preparação técnica de um produto de forma que possa ser facilmente adaptado a um mercado específico após a fase de engenharia"3 $^{3}$ (SANDRINI, 2008, p.1);

- localização diz respeito à "prestação de serviços e tecnologias para o manejo do multilinguismo através do fluxo global de informações" ${ }^{4}$ (SANDRINI, 2008, p.2).

A tradução "é o processo base da localização" (RAMOS, 2015, p. 34). Em outras palavras, “é um ramo dos estudos da tradução que consiste em traduzir os conteúdos de um 
texto, software ou página da internet, adaptando-o à cultura de destino" (RAMOS, 2015, p. 34), ou seja, em um projeto de localização, deve-se considerar vários processos que vão muito além do que apenas a tradução.

Fernández-Costales (2010) questiona a utilização do termo “internacionalização" para sítios universitários quando esse coincide com a prática computacional de permitir que os sítios eletrônicos sejam tecnicamente adaptáveis, ou seja, "uma web internacionalizada é aquela que pode ser traduzida a um idioma de destino desde que tenha sido desenhada sob determinados parâmetros"5 (p. 505). Nesse sentido, a "internacionalização" seria uma questão técnica que permite, por exemplo, que uma página possa ser disponibilizada em alfabeto latino e em caracteres chineses. Segundo o autor, não é possível confirmar que o processo de adaptação dos sítios eletrônicos universitários possa ser considerado como localização, sendo o termo 'tradução de sítios universitários' mais adequado para denominar esse ato comunicativo.

\section{Aspectos da Tradução e Internacionalização de Sítios Eletrônicos}

Os sítios eletrônicos podem ser considerados como "uma forma de propaganda" 6 (YUNKER, 2003, p. 4 apud SANDRINI, 2008 p. 9). Para se manterem atual e ter o efeito desejado, todos os itens relacionados a um sítio eletrônico, como textos, imagens, áudio, vídeo, arquivos, documentos e fóruns de discussão, têm um ciclo de vida no que diz respeito ao seu conteúdo. Isso quer dizer que alguns desses itens, ao sofrerem adaptações no texto-fonte, devem ser também alterados na tradução.

Sandrini (2008) aponta algumas considerações para a tradução e localização de sítios eletrônicos:

a) adaptar as informações específicas do sítio eletrônico, como data, hora, números ou valores, para a língua-alvo;

b) eliminar referências específicas a questões políticas e religiosas;

c) ter especial atenção aos gráficos, símbolos e cores, que podem estar profundamente ligados à cultura do país de origem, mas não à do país-alvo; e

d) evitar o uso de imagens de bandeiras para determinar a língua para a qual o sítio eletrônico será traduzido.

Sandrini (2018) explica por que não é aconselhável o uso de bandeiras nacionais quando se trata de tradução de sítios universitários: 
Evite o uso de bandeiras nacionais, esse é um mau hábito nascido nos primórdios da $w e b$. Uma bandeira nacional representa pouco de uma língua em sua totalidade: que tipo de bandeira devemos utilizar para representar o espanhol? A bandeira da Argentina, da Espanha, do México, da Guatemala ou mesmo a bandeira dos Estados Unidos [...]? (SANDRINI, 2008, p. 15) ${ }^{7}$

O conteúdo da internet possui uma dimensão multilíngue, uma vez que a internet é linguisticamente plural. O processo técnico da localização de sítios eletrônicos envolve o trabalho não apenas com línguas, mas também com imagens, vídeos, cores, a disposição dos elementos textuais a serem lidos, o tipo de letra, a seleção dos conteúdos e o modo como são apresentados (FOUCES, 2012).

Ao tradutor cabe a tradução de conteúdos estáticos e de alguns conteúdos dinâmicos, enquanto à equipe técnica do sítio cabe a atualização desse conteúdo. Algumas universidades não traduzem o nome da instituição, elemento estático, pois desejam manter a própria identidade em seus sítios eletrônicos (FERNÁNDEZ-COSTALES, 2010).

A redução de conteúdo é outra estratégia abordada por Fernández-Costales (2010). Segundo ele, muitos sítios traduzidos contêm menos conteúdo que os originais, pois o objetivo é mostrar somente as informações relevantes ao público internacional. As informações acadêmicas e científicas, bem como o perfil da instituição são elementos relevantes que a diferenciam de outras instituições. Os agentes principais na tomada de decisões para a internacionalização de um sítio eletrônico são o reitor e o próprio governo, levando-se sempre em consideração as particularidades de cada universidade.

\section{Os Sítios Eletrônicos Universitários}

Fernández-Costales (2010) é, até onde se pôde verificar, o único autor a investigar amplamente os sítios eletrônicos universitários na perspectiva dos estudos da tradução. Ele buscou manter um ponto de vista multidisciplinar por considerar que essa estratégia pode favorecer uma reflexão mais próxima da problemática que envolve o assunto.

Para Fernández-Costales (2010), a internet desempenha três funções fundamentais, quais sejam: informar, promover e comunicar. Trata-se de um meio no qual a relação com o usuário é um elemento inerente ao desenvolvimento da própria web. De acordo com o autor, atualmente quase todas as instituições de ensino superior na Europa têm um sítio eletrônico que oferece informações ao usuário, o que parece sinalizar que as universidades têm ciência da importância de um sítio eletrônico. 
Outro aspecto levantado por Fernández-Costales (2010) refere-se aos usuários dos sítios universitários, aqueles a quem se destinam as páginas. O público-alvo mais imediato é a comunidade universitária, ou seja, os estudantes matriculados, os graduados e os egressos, os professores e pesquisadores, bem como todos os trabalhadores da instituição. Para esse público, cumprem-se duas das três funções mencionadas anteriormente, a informativa e a comunicativa, ou seja, os sítios eletrônicos servem para oferecer informações e conteúdos indispensáveis aos estudantes e aos trabalhadores da instituição ao mesmo tempo que funcionam como uma ferramenta de comunicação entre a instituição e o usuário, fornecendo, por exemplo, informações sobre as datas das provas, os regulamentos que regem as normas da instituição e os canais que permitem aos alunos entrar em contato com a administração ou com o professor.

Foi devido à evolução internacional que os sítios eletrônicos universitários deixaram de ser apenas ferramentas de informação e comunicação para se transformarem em um ponto de contato da instituição com o restante do mundo. Nesse sentido, a terceira e principal função entra em cena: a promocional. Não se trata apenas de passar informações aos usuários, mas de facilitar a comunicação e a interação com a própria instituição. Os sítios eletrônicos são ferramentas promocionais que contribuem para melhorar a visibilidade internacional das universidades, permitindo a atração de estudantes e pesquisadores estrangeiros.

Fernández-Costales (2010) vê na função promocional o elemento que mais evoluiu nos sítios eletrônicos nos últimos anos. Para ele, é notável a relevância concedida a esse fator pelas universidades, uma vez que estão incluindo cada vez mais conteúdo em seus sítios na intenção de atrair futuros estudantes e pesquisadores.

A maior parte dos sítios eletrônicos europeus está traduzida para o inglês, sendo a tradução aplicada sobre os elementos textuais. Pode haver, no entanto, diferenças entre os conteúdos estáticos (i.e., elementos com ciclo de vida mais duradouro) e os conteúdos dinâmicos (i.e., elementos que variam constantemente, como os eventos, as notícias sobre a universidade, a agenda e atualidade sobre temas de interesse). $\mathrm{O}$ autor afirma que os sítios eletrônicos são 'organismos vivos', de modo que uma tradução nunca poderá ser considerada acabada (FERNÁNDEZ-COSTALES, 2010, p. 483).

O referido autor também afirma que, para produzir sítios úteis e acessíveis, é necessário que se tornem multilíngues, incluindo uma tradução para vários idiomas. Esse multilinguismo pode referir-se aos interesses particulares de cada instituição: por exemplo, se a universidade estiver interessada em atrair alunos chineses, deve traduzir seu sítio eletrônico ao idioma chinês. 
Isso quer dizer que a instituição pode selecionar as línguas-alvo conforme os interesses políticos, culturais e econômicos.

Fernández-Costales (2010) afirma que os sítios eletrônicos são janelas abertas ao mundo de cada universidade, com atualizações constantes de seu conteúdo a fim de proporcionar informações da comunidade universitária e tentar melhorar sua visibilidade internacional.

\section{Metodologia}

Esta seção descreve a metodologia de coleta e análise dos dados para a realização do presente trabalho. O sítio eletrônico do PPCSA (Programa de Pós-Graduação em Ciências da Saúde), nota 5 pela CAPES, foi escolhido por ter sido o primeiro a ser desenvolvido no novo padrão UFU de internacionalização. Em contrapartida, o sítio eletrônico do PPGECO (Programa de Ecologia e Conservação de Recursos Naturais) da Universidade Federal de Uberlândia (UFU) foi escolhido por ter a mesma nota pela CAPES e por estar parcialmente traduzido.

Os menus e outros itens gerais da página principal dos sítios eletrônicos do PPGECO e do PPCSA foram extraídos manualmente e lançados em quadros gerados no programa Microsoft Word. O sítio do PPCSA foi utilizado como base para a seleção e tradução de itens similares no sítio eletrônico do PPGECO.

Mais especificamente, os itens gerais do sítio eletrônico do PPCSA foram lançados em um quadro contendo as proposições de alterações da tradução, caso houvesse problemas. Por sua vez, os itens gerais do sítio do PPGECO foram lançados em outro quadro, juntamente com uma proposta de sua tradução para a língua inglesa.

O quadro referente ao PPCSA foi dividido em quatro colunas, dispostas nesta ordem:

- Áreas: áreas com itens traduzíveis;

- TF_PT: texto-fonte em português;

- TO_EN: tradução original em inglês;

- Proposta alteração: sugestão de reparo de erros gramaticais e de tradução.

Já o quadro referente ao PPGECO foi dividido em quatro colunas, nesta ordem:

- Itens: $\quad$ áreas com itens análogos àqueles do PPCSA; 
- TF_PT: texto-fonte em português;

- Tradução_EN: tradução original em inglês;

- Prop. Tradução: $\quad$ proposta de tradução para os itens não traduzidos;

- Prop. Inclusão: $\quad$ proposta de inclusão de itens no sítio.

\section{Análise dos Dados}

Observou-se nesta pesquisa, que os sítios eletrônicos dos programas estudados (i.e., PPCSA e PPGECO) configuram-se como um material informativo e comunicativo, pois se voltam a um público-alvo composto por estudantes matriculados, egressos, professores, pesquisadores e trabalhadores da instituição. Os sítios não se configuram como uma "intranet", com acesso exclusivo para usuários internos, mas suas versões em português trazem conteúdos de interesse específico dos estudantes, professores e técnicos atuais e prospectivos, como informações sobre horários de aulas e editais de processos seletivos.

Do ponto de vista promocional, embora ambos apresentem uma tentativa de se tornarem um ponto de contato da instituição com o restante do mundo (seja em inglês ou em português), nenhum deles explora contundentemente a linguagem persuasiva e os aspectos não textuais, como imagens, vídeos e cores (i.e., há apenas um vídeo e três imagens no sítio eletrônico do PPCSA, algumas das quais se repetem). Não obstante, pode-se considerar que a existência e a manutenção de ambos por si só evidenciam uma tentativa de promover a própria instituição, melhorando sua visibilidade, nacional e internacional, bem como a atração de estudantes.

Considerando a página principal do sítio eletrônico do PPCSA (cf. Figura 2), vê-se, tal qual observado por Fernández-Costales (2010), que a página traduzida apresenta menos conteúdo que a página original. Mais especificamente, aquela dispõe apenas os conteúdos supostamente mais relevantes ao público internacional.

O único vídeo disponível na página, embora traga informações que precisam ser constantemente atualizadas, como os números da UFU (e.g., quantitativo de estudantes), constitui-se como um elemento estático, datado de 2015. Esse vídeo já se encontra dublado, mas poderia também estar legendado para que o público internacional pudesse escolher a melhor forma de assistir ao vídeo. Trata-se de um vídeo que poderia receber maior atenção, uma vez que é a única fonte de informação, em inglês, disponível para o público internacional, considerando-se, inclusive, que a página da UFU está disponível apenas em português (cf. Figura 3). 
Figura 2 - Página inicial em português, do PPCSA da UFU
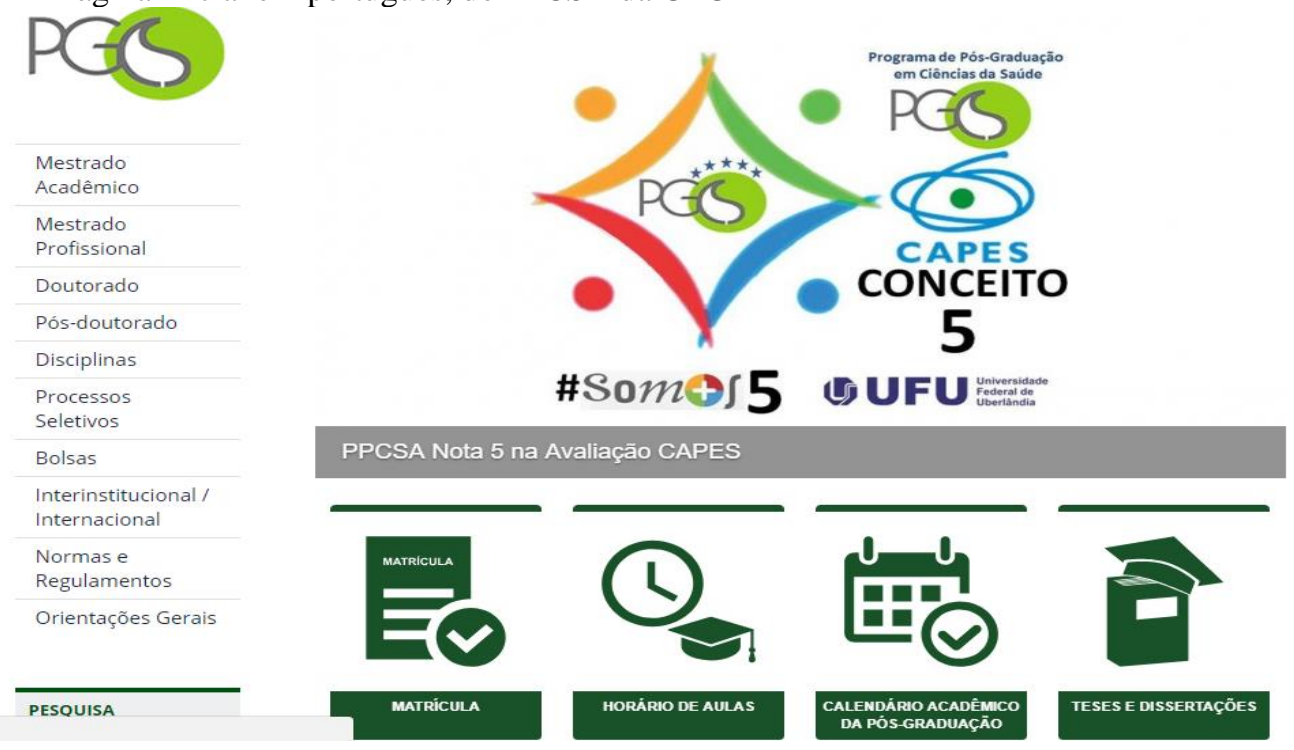

Fonte: Instantâneo do sítio eletrônico do Programa de Pós-graduação em Ciências da Saúde da UFU. Disponível em: http://www.ppcsa.famed.ufu.br. Acesso em: 05 maio 2018.

Figura 3: Página inicial, em inglês traduzido, do PPCSA da UFU
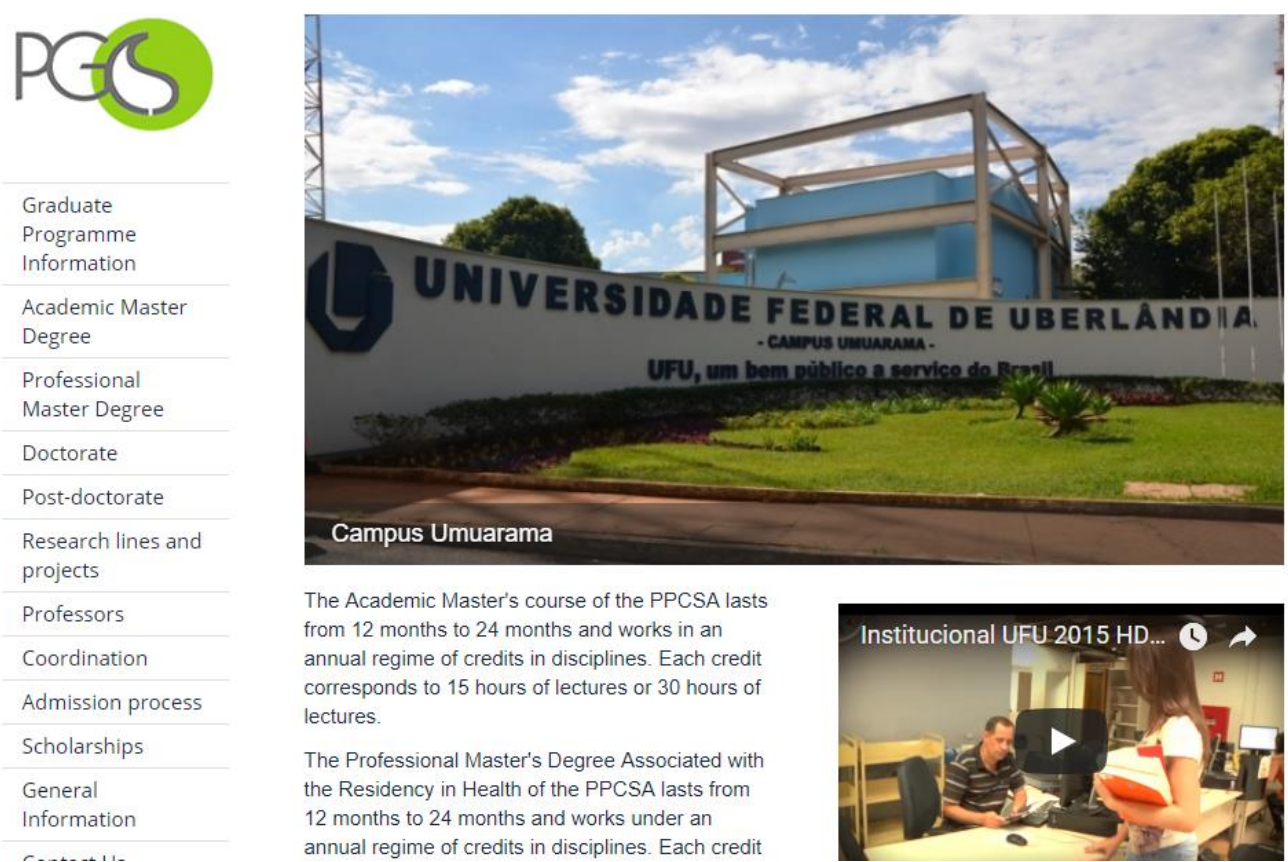

The Academic Master's course of the PPCSA lasts from 12 months to 24 months and works in an annual regime of credits in disciplines. Each credit corresponds to 15 hours of lectures or 30 hours of lectures.

The Professional Master's Degree Associated with the Residency in Health of the PPCSA lasts from 12 months to 24 months and works under an annual regime of credits in disciplines. Each credit

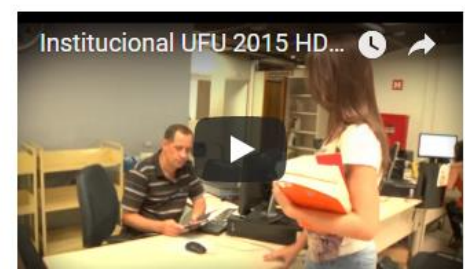

Fonte: Instantâneo do sítio eletrônico do Programa de Pós-graduação em Ciências da Saúde da UFU. Disponível em: http://www.ppcsa.famed.ufu.br. Acesso em: 05 maio 2018.

Como aspecto positivo do sítio eletrônico do PPCSA, destaca-se o fato de que informa ao público estrangeiro como participar do programa, conforme disponível na página sobre "Scholarships". Trata-se, portanto, de um item preocupado com a internacionalização da universidade e que não consiste em uma tradução do conteúdo já disponibilizado em língua portuguesa. 


\section{DEFINITIONS:}

Foreign students interested in applying to our graduate program (Master and Doctorate) are welcome and may participate freely in the selection process.

REQUIREMENTS:

Should the foreign student be approved in all stages of the Program selection process, this individual will need to meet the following requirements: I. Prove their undergraduate studies and have their graduation diploma admitted through the criteria established in the Program Rules; II. Prove their legal status in national territory; III. Non-lusophone candidates should present the approval certificate from PROFLIN Portuguese Language from ILEEL-UFU (http://www.ileel.ufu.br/proflin) or the Certificate CELPE-BRAS (http://www.mec.gov.br/sesu/celp.shtm), observing the same conditions and the same validities as all other proficiency certificates. (UNIVERSIDADE FEDERAL DE UBERLÂNDIA. Faculdade de Medicina. Disponível em: http://www.ppcsa.famed.ufu.br/en/servicos/scholarship. Acesso em: 05 maio 2018.)

Cabe apontar que as normas do programa não estão disponíveis em língua inglesa, que as páginas do PROFLIN e do CELPE-BRAS não estão disponíveis em inglês (sendo que o link correto para o CELPE-BRAS seria http://celpebras.inep.gov.br/inscricao/) e que não fica clara a diferença entre a página "Scholarships" e uma especificamente denominada de "Admission process".

A página sobre "Admission process" parece ser uma tradução da página sobre processo seletivo para brasileiros, uma vez que nada menciona sobre a proficiência do candidato em língua portuguesa, conforme disposto no excerto a seguir:

Every candidate should present proficiency of the English language. The English language proficiency certificate should be presented upon enrolment; this should be signed by the head of the issuing body. For the Doctorate Degree, proof of proficiency will not be demanded for the English language. Proof in the proficiency in one other language should be presented in the maximum 24 months after the enrolment date. For the Master Degree, the following proficiency certificates will be accepted acquired as of October 2014, emitted by:

- PROFLIN-ILEEL-UFU (http://www.ileel.ufu.br/proflin)

- Higher education institutions;

- Graduate Programs recognized or recommended by CAPES.

The following official exams acquired as of October 2011 emitted by:

- Cambridge from the Intermediate level.

- Michigan.

- Toefl with a minimum of 500 points in the printed test or 230 in the electronic test.

- TESE Prime with a minimum of 60 points. (UNIVERSIDADE FEDERAL DE UBERLÂNDIA. Faculdade de Medicina. Disponível em: http://www.ppcsa.famed.ufu.br/en/servicos/admission-process. Acesso em: 05 maio 2018.)

A página do PPGECO também disponibiliza menos conteúdo em sua versão em inglês. Entretanto, não é possível tecer considerações relevantes porque a página inicial é a única que 
efetivamente traz informações em língua inglesa, estando seus menus, embora em menor quantidade em relação à página original, ainda em português (cf. Figuras 4 e 5).

Figura 4 - Página principal, em português do Brasil, do sítio eletrônico do PPGECO da UFU

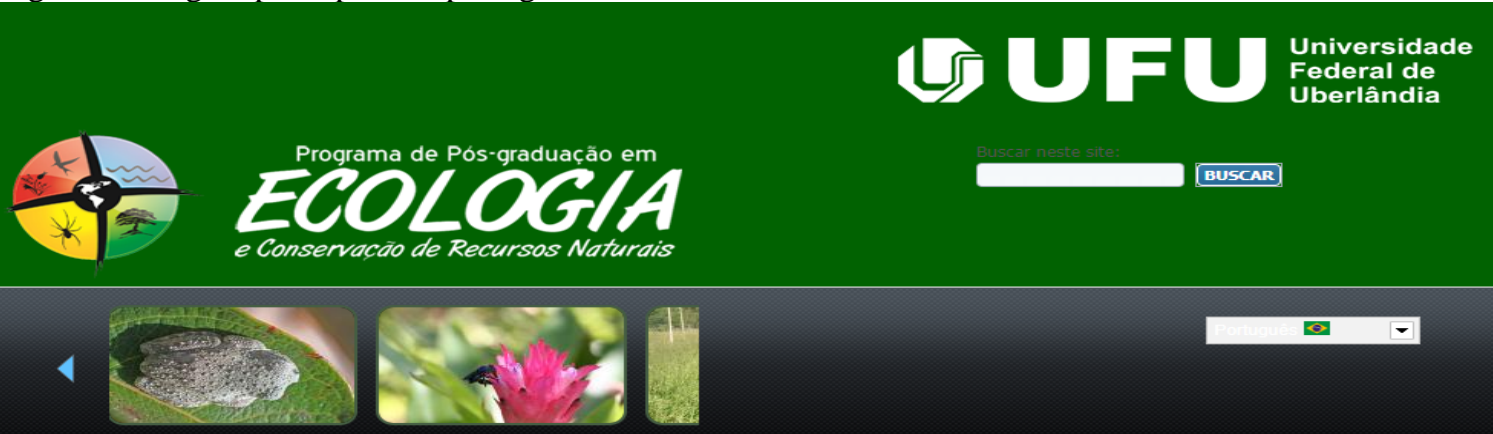

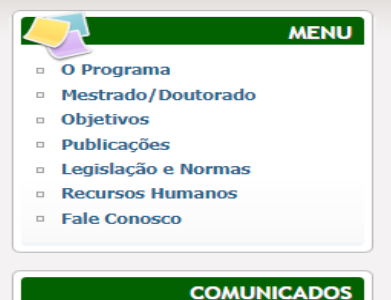
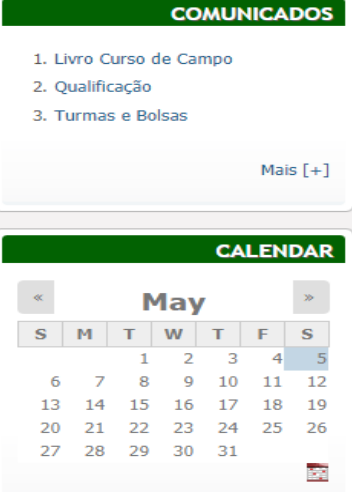

\section{OUTRAS INFORMAÇõES \\ Imagens \\ Vídeos}

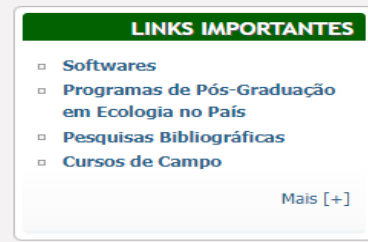

Mais $[+]$
Bem-vindo

Aproveitamento de Estudos

Eleições 2018- Coordenador e Membro do Colegiado

Exame de Qualificaça (doutorado)

Horário de Aulas Primeiro Semestre 2018

Orientações Defesas- Mestrado e Doutorado

Instruções para discentes pós defesa

Passe Escolar

Portal do Aluno-Primeiro Acesso

O Programa de Pós-Graduação em Ecologia e Conservação de Recursos Naturais da Universidade Federal de Uberlândia foi criado em 1999 (Resolução 05/98 de 26/06/1998 do CONSUN). Dentre os objetivos do Programa estão a formação de recursos humanos qualificados para lidar com as questôes ambientais regionais e nacionais e gerar conhecimentos sobre os processos biológicos dos ecossistemas, buscando auxiliar na resolução de problemas ambientais. O repasse de informações para a sociedade é também uma preocupação constante procurando-se desenvolver conceltos e valores sobre a importâncla da conservaçăo da natureza. A infra-estrutura do programa e adequada e no aspecto das instalaçôes físicas destaca-se a sala de informática para uso dos alunos, com mais de dez computadores, todos conectados à internet. O Proarama de Pós-Graduacão em Ecoloqia e Conservacão de que hoje trabal outros órgãos públicos e emprosas particulares. O programa está sediado no Instituto de Biologia da Universidade Federal de Utherlândia e é RECOMENDADO pela CAPES (Conceito 5 na área de Biodiversidade):

O curso de mestrado foi recomendado pelo Grupo Técnico Consultivo da CAPES em 09/04/1999 e reconhecido pelo MEC através da Portaria no. 1734 de 07 de dezembro de 1999.

A recomendação do curso de doutorado foi oficializada pelo Ofício no. 377/2004/CTC/CAPES em 14 de outubro de 2004.

Até o mês de outubro de 2017 o curso de mestrado já titulou 252 alunos e o curso de doutorado 51.

\section{Programa recomendado pela CAPES}

\section{Conceito 5 na área de Biodiversidade}

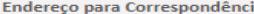

Programa de Pós-Graduação em Ecologia e Conservação de Recursos Naturais

Campus Umuarama, bloco 2D, sala 26

Uberlândia - MG - CEP 38400-90

Secretária do Programa de Pós-Graduação

Juliana Pinheiro

E-mail: ecologia@umuarama.ufu.br

Telefone: (34) 3225-8641

Coordenador do Programa de Pós-Graduação:

Telefone: (34) 3225-8641

E-mail: poliveiragm@gmail.com

Página: http://mww.ppgeco.tb.ufu.br/en/home

Este sitio é melhor visualizado no Firefox 3.0 (ou superior) ou IE 7.0 (ou superior) com resolucãos.

Fonte: instantâneo do sítio eletrônico do Programa de Pós-Graduação em Ecologia e Conservação de Recursos Naturais. Disponível em: http://www.ppgeco.ib.ufu.br. Acesso em: 05 maio 2018. 
Figura 5 - Página principal, parcialmente traduzida para o inglês, do sítio eletrônico PPGECO da UFU

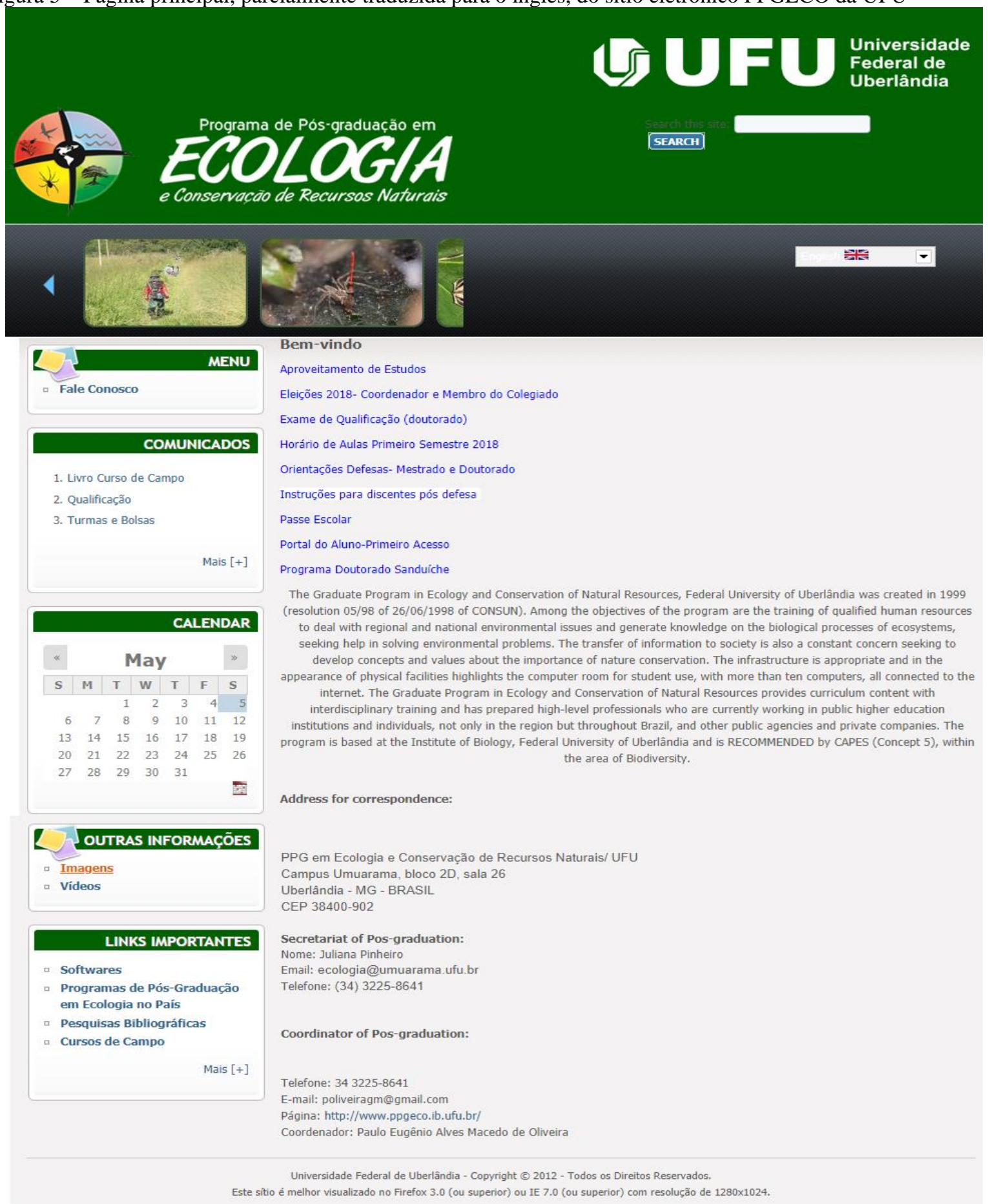

Fonte: instantâneo do sítio eletrônico do Programa de Pós-graduação em Ecologia e Conservação de Recursos Naturais. Disponível em: http://www.ppgeco.ib.ufu.br. Acesso em: 05 maio 2018.

Do ponto de vista da tradução e internacionalização, conforme mostrado nas Figuras 6 e 7, os sítios do PPCSA e do PPGECO mantiveram o nome da instituição Universidade Federal de Uberlândia sem alteração, mas optaram pela denominação dos respectivos programas em língua inglesa. Todavia, o sítio do PPGECO usa o recurso de imagem da bandeira nacional para 
designar a língua para a qual foi traduzido, ao passo que o sítio eletrônico do PPCSA, em conformidade com as recomendações de Sandrini (2008) e de Fernández-Costales (2010), não utilizou a imagem da bandeira nacional para sinalizar a língua à qual foi traduzido.

O uso de uma bandeira se revela ainda mais problemático em um sítio eletrônico quando se observa que a ortografia adotada não condiz com a localidade aparentemente indicada: por exemplo, o sítio do PPGECO utiliza a bandeira britânica, mas oscila ao empregar ortografia estadunidense em palavras como "program".

Figura 6 - Página inicial do sítio eletrônico do PPGECO da UFU

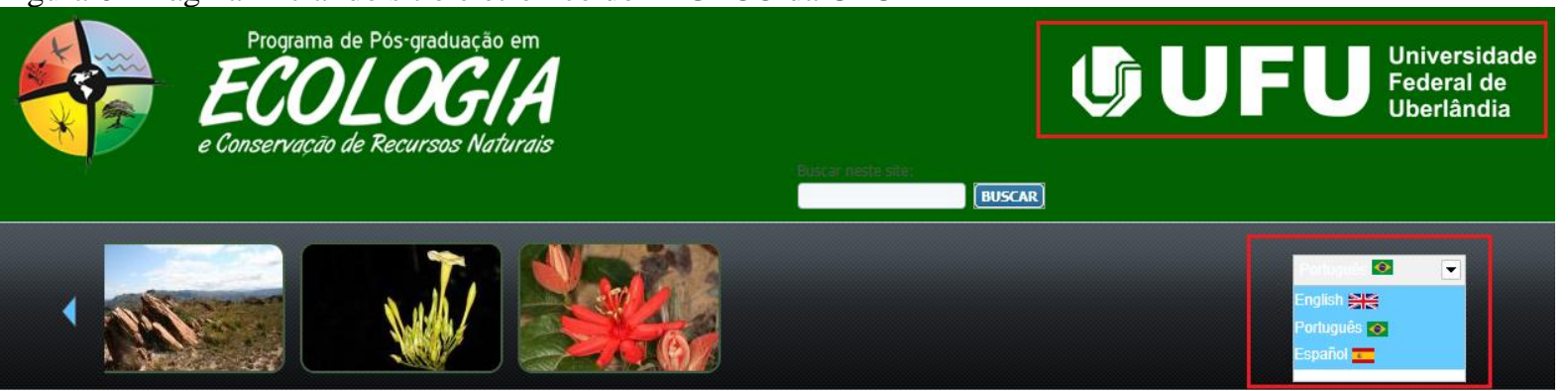

Fonte: instantâneo do sítio eletrônico do Programa de Pós-graduação em Ecologia e Conservação de Recursos Naturais da UFU. Disponível em: http://www.ppgeco.ib.ufu.br. Acesso em: 05 maio 2018.

Figura 7: Página inicial do sítio eletrônico do PPCSA da UFU.

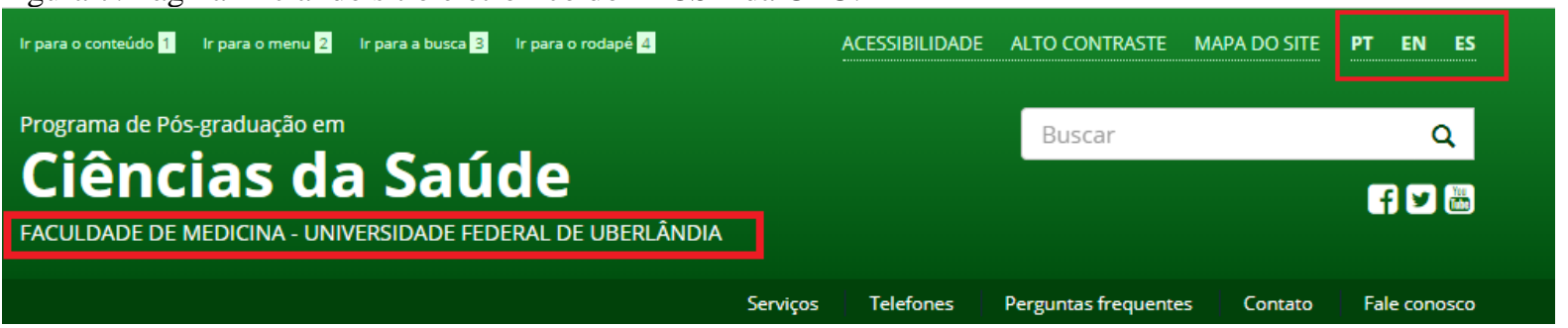

Fonte: instantâneo do sítio eletrônico do Programa de Pós-graduação em Ciências da Saúde da UFU. Disponível em: http://www.ppcsa.famed.ufu.br. Acesso em: 05 maio 2018.

Além dessa inconsistência, foram identificados outros problemas de ordem linguística e informacional nos sítios eletrônicos, a saber:

- erros de ortografia, como "pos-graduation" (PPGECO);

- inconsistência terminológica, como referência ao programa de pós-graduação ora como "graduate program", ora como "postgraduate program" (PPCSA), bem como uso de "master in health sciences" em vez de "master's in health sciences" (PPCSA); 
- erros de tradução, como uso de "disciplines" em vez de "courses" em referência a disciplinas (PPCSA); e uso de "course" em vez de "program" em referência ao curso ou programa (PPCSA);

- falhas de internacionalização, com a não explicitação de questões marcadamente culturais, como o que seria um "Concept CAPES” (PPGECO e PPCSA);

- não atualização de informações, como a nota "4" pela CAPES para o PPCSA, que, na verdade, obteve nota 5 na avaliação quadrienal de 2017 (cf. http://avaliacaoquadrienal.capes.gov.br/resultado-da-avaliacao-quadrienal2017-2);

- links para acesso a sítios eletrônicos apenas em português no sítio do PPCSA, como é o caso do link no rodapé para acesso à página da UFU e do documento, em formato .doc, para informações sobre os professores e suas respectivas temáticas e linhas de pesquisa; e

- inconsistência, no sítio do PPCSA, entre o conteúdo acessado pelo item "Contact Us" no menu horizontal superior, que acessa um formulário de contato, e no menu vertical esquerdo, que disponibiliza o endereço físico e o correio eletrônico do programa.

Tendo em vista o sítio eletrônico do PPCSA, identificou-se que os itens traduzidos são aqueles que transmitem ao usuário estrangeiro informações acerca da instituição; entretanto, há problemas de linguagem e tradução que ainda precisam ser sanados, conforme já mencionado. O Quadro 1 contém uma coluna com a proposta de melhoria das palavras e/ou expressões adotadas nos menus da página principal do PPCSA.

\begin{tabular}{|c|c|c|c|}
\hline Áreas & TF_PT & Tradução_EN & Proposta de Alteração \\
\hline Cabeçalho & $\begin{array}{l}\text { Programa de Pós-graduação } \\
\text { em Ciências da Saúde } \\
\text { FACULDADE DE } \\
\text { MEDICINA - } \\
\text { UNIVERSIDADE FEDERAL } \\
\text { DE UBERLÂNDIA }\end{array}$ & $\begin{array}{l}\text { Postgraduate Program in } \\
\text { Health Sciences } \\
\text { FACULDADE DE } \\
\text { MEDICINA - } \\
\text { UNIVERSIDADE FEDERAL } \\
\text { DE UBERLÂNDIA }\end{array}$ & $\begin{array}{l}\text { Graduate Program in Health } \\
\text { Sciences }\end{array}$ \\
\hline Rodapé & $\begin{array}{ll}\text { UFU } & \\
- & \text { A Universidade } \\
- & \text { Campi } \\
- & \text { Faculdades e Institutos } \\
- & \text { Bibliotecas } \\
- & \text { Hospitais } \\
- & \text { Restaurantes } \\
- & \text { Fundações } \\
- & \text { Apoio Estudantil } \\
- & \text { Internacionalização }\end{array}$ & $\begin{array}{l}\text { UNIVERSITY } \\
-\quad \text { Federal University of } \\
\text { Uberlândia (only in } \\
\text { Portuguese) }\end{array}$ & $\begin{array}{l}\text { - Universidade Federal de } \\
\text { Uberlândia (Portuguese } \\
\text { only) }\end{array}$ \\
\hline
\end{tabular}


Quadro 1 - Sítio eletrônico do Programa de Pós-graduação em Ciências da Saúde

\begin{tabular}{|c|c|c|c|}
\hline Áreas & TF_PT & Tradução_EN & Proposta de Alteração \\
\hline \multirow{4}{*}{ Rodapé } & - $\quad$ Uso da marca UFU & & \\
\hline & \begin{tabular}{ll}
\multicolumn{2}{l}{ FAMED } \\
- & A Faculdade \\
- & Docentes \\
- & Graduação em \\
& Enfermagem \\
- & Graduação em Medicina \\
- & Graduação em Nutrição \\
- & Pós-graduação Stricto \\
& Sensu \\
- & Pós-graduação Lato \\
& Sensu
\end{tabular} & $\begin{array}{l}\text { GRADUATION } \\
\text { PROGRAMME } \\
-\quad \text { Academic Master Degree } \\
\text { - } \quad \begin{array}{l}\text { Professional Master } \\
\text { Degree }\end{array} \\
\text { - } \quad \begin{array}{l}\text { Research lines and } \\
\text { projects }\end{array}\end{array}$ & \begin{tabular}{cl}
\multicolumn{2}{l}{ GRADUATE PROGRAM } \\
$-\quad$ Academic Master's \\
Degree \\
- $\quad$ Professional Master's \\
Degree
\end{tabular} \\
\hline & \begin{tabular}{ll}
\multicolumn{2}{l}{ PPCSA } \\
- & O Programa \\
- & Mestrado Acadêmico \\
- & Mestrado Profissional \\
- & Doutorado \\
- & Docentes \\
- & Processos Seletivos \\
- & Interestitucional / \\
& Internacional \\
- & Normas e Regulamentos \\
- & Orientações Gerais \\
\end{tabular} & \begin{tabular}{ll}
\multicolumn{2}{l}{ STUDY WITH US } \\
- & Admission process \\
- & Scholarships \\
- & General Information
\end{tabular} & - $\quad$ Ethics \\
\hline & $\begin{array}{ll}\text { SAIBA MAIS } \\
-\quad \text { Mapa do Site } \\
-\quad \text { Perguntas Frequentes } \\
-\quad \text { Fale conosco } \\
\end{array}$ & $\begin{array}{l}\text { QUESTIONS? } \\
-\quad \text { Contact Us }\end{array}$ & $\begin{array}{l}\text { FURTHER INFORMATION } \\
-\quad \text { Find us }\end{array}$ \\
\hline \multirow{13}{*}{$\begin{array}{l}\text { Menu Superior } \\
\text { Horizontal }\end{array}$} & Ir para o conteúdo & Go to content & \\
\hline & Ir para o menu & Go to menu & \\
\hline & Ir para a busca & Go to search & \\
\hline & Ir para o rodapé & Go to footer & \\
\hline & Acessibilidade & ACCESSIBILITY & \\
\hline & Alto Contraste & HIGH CONTRAST & \\
\hline & Mapa do Site & SITEMAP & SITE MAP \\
\hline & $\mathrm{PT} / \mathrm{EN} / \mathrm{ES}$ & $\mathrm{PT} / \mathrm{EN} / \mathrm{ES}$ & \\
\hline & Serviços & NA & \\
\hline & Telefones & NA & \\
\hline & Perguntas Frequentes & Frequently questions & FAQ \\
\hline & Contato & Localization & Find Us \\
\hline & Fale conosco & Contact Us & Contact Us \\
\hline \multirow{13}{*}{ Menu Vertical } & NA & $\begin{array}{l}\text { Graduate Programme } \\
\text { Information }\end{array}$ & Information about the Program \\
\hline & Mestrado Acadêmico & Academic Master Degree & Academic Master's Degree \\
\hline & Mestrado Profissional & Professional Master Degree & Professional Master's Degree \\
\hline & Doutorado & Doctorate & Doctoral Degree \\
\hline & Pós-doutorado & Post-doctorate & Postdoctoral \\
\hline & \begin{tabular}{lc}
\multicolumn{2}{l}{ PESQUISA } \\
$-\quad$ Projeto \\
\end{tabular} & Research lines and projects & \\
\hline & $\begin{array}{l}\text { MEMBROS } \\
-\quad \text { Docentes }\end{array}$ & Professors & Faculty \\
\hline & \begin{tabular}{l}
\multicolumn{2}{l}{ O PROGRAMA } \\
$-\quad$ Mural de Coordenadores
\end{tabular} & Coordination & \\
\hline & Processos Seletivos & Admission Process & \\
\hline & $\begin{array}{l}\text { Interestitucional / } \\
\text { Internacional }\end{array}$ & Scholarships & \\
\hline & Orientações Gerais & General Information & \\
\hline & Fale conosco & Contact Us & Find Us \\
\hline & Links & Important Links & \\
\hline
\end{tabular}

Fonte: elaboração própria.

GOIS, Helda Maria Falcão de; DA SILVA, Igor Antônio Lourenço. A tradução de dois sítios eletrônicos da Universidade Federal de Uberlândia sob o viés da internacionalização. Belas Infiéis, Brasília, v. 9, n. 4, p. 75-100, jul./set., 2020.

e-ISSN: 2316-6614. DOI: doi.org/10.26512/belasinfieis.v9.n4.2020.27494 
O Quadro 1 contém as áreas da página principal do sítio eletrônico do PPCSA. Para as inconsistências localizadas, procedeu-se a uma proposta de alteração, disposta na quarta coluna. O cabeçalho do sítio contendo o nome do Programa de Pós-graduação em Ciências da Saúde foi traduzido por Postgraduate Program in Health Sciencies; logo abaixo no menu vertical, a versão em inglês do sítio apresenta algumas informações acerca do programa, que é então referido como "Graduate Programme", consistindo, portanto, em uma inconsistência terminológica. Logo abaixo, os ícones que apresentam os programas de Mestrado Acadêmico e Mestrado Profissional foram traduzidos por "Academic Master Degree" e "Professional Master Degree", sendo que esses termos deveriam ser grafados como "Academic Master's Degree" e "Professional Master's Degree". O item referente aos professores dos cursos foi traduzido por "Professors", que pode ensejar a ideia de que se trata apenas de professores titulares (e.g., no Reino Unido), enquanto o corpo docente na verdade também inclui professores adjuntos e associados, razão pela qual é sugerido o termo mais amplo "Faculty". Além disso, utilizou-se a mesma expressão "Contact Us" para representar duas situações diferentes: no menu horizontal superior, a expressão refere-se ao contato direto do usuário com a coordenação do curso por meio de um formulário; já no menu vertical esquerdo, remete ao endereço físico do curso para troca de correspondências e/ou visitas pessoais, podendo ser, nesse caso, registrado como "Find Us". Além disso, o título "General Information" no Rodapé da página, é confuso em relação ao item "Information about the program" proposto, o que motivou a sugestão de "Ethics", tendo em vista o atual conteúdo específico da página, ou a sugestão de "Further Information", caso haja previsão de novos conteúdos.

Ao analisar o conteúdo existente dentro dos ícones da página principal, mais especificamente quando dispõem informações sobre os respectivos programas, identificaramse outras inconsistências como a não explicação da nota atribuída pela CAPES ao programa. Essa falta de explicação pode comprometer o entendimento do público internacional, pois se trata de uma nota que vai de 1 a 7 , sendo que o público leigo e de outras culturas pode interpretar "1" como a melhor nota, em vez do "7", ou mesmo entender que se trata de uma pontuação no âmbito de um intervalo mais "clássico" de 0 a 100 ou de 0 a 10. A informação sobre a CAPES e sobre a nota atribuída ao programa poderia ser incluída da seguinte maneira:

The Brazilian Ministry of Education's Coordination for the Improvement of Higher Education Personnel (CAPES in its acronym in Portuguese) plays a fundamental role in the expansion and consolidation of the graduate programs (for both master's and doctor's degrees) in all federated states in Brazil. ${ }^{8}[. .$.$] The CAPES grades range from$ 
01 to 07: grades 1 and 2 disqualifies the graduate program; 3 means regular performance, with minimum quality; 4 is considered a good performance; 5 is the maximum grade for programs providing master's degree only; grades 6 and 7 indicate performance of high international standard. ${ }^{9}$

A seguir, apresenta-se, no Quadro 2, uma revisão do conteúdo da página inicial do sítio eletrônico do PPCSA.

Quadro 2 - Tradução original e proposta de revisão para a página inicial do PPCSA

\begin{tabular}{|c|c|}
\hline Tradução Original & Proposta de Revisão \\
\hline $\begin{array}{l}\text { The Academic Master's course of the PPCSA lasts } \\
\text { from } 12 \text { months to } 24 \text { months and works in an annual } \\
\text { regime of credits in disciplines. Each credit } \\
\text { corresponds to } 15 \text { hours of lectures or } 30 \text { hours of } \\
\text { lectures. }\end{array}$ & $\begin{array}{l}\text { The Academic Master's program of the PPCSA can } \\
\text { be completed within } 12 \text { months to } 24 \text { months. } \\
\text { Students are required to complete course credits, } \\
\text { each corresponding to } 15 \text { hours or } 30 \text { hours of } \\
\text { lectures. }\end{array}$ \\
\hline $\begin{array}{l}\text { The Professional Master's Degree Associated with } \\
\text { the Residency in Health of the PPCSA lasts from } 12 \\
\text { months to } 24 \text { months and works under an annual } \\
\text { regime of credits in disciplines. Each credit } \\
\text { corresponds to } 15 \text { hours of lectures or } 30 \text { hours of } \\
\text { lectures. }\end{array}$ & $\begin{array}{l}\text { The Professional Master's program of the PPCSA is } \\
\text { associated with a residency in Health and can be } \\
\text { completed within } 12 \text { months to } 24 \text { months. Students } \\
\text { are required to complete course credits, } \\
\text { corresponding to } 15 \text { hours or } 30 \text { hours of lectures. }\end{array}$ \\
\hline
\end{tabular}

Observe-se, pelo Quadro 2, que na página inicial do programa sequer há informações, em língua inglesa, sobre o doutorado oferecido pelo PPCSA. Além disso, as descrições iniciais dos mestrados profissional e acadêmico são pouco elucidativas quanto à diferença entre eles.

Já o sítio eletrônico do PPGECO, apesar da indicação de versão em inglês pelo uso de uma bandeira britânica, encontra-se praticamente não traduzido. O Quadro 3 lança uma proposta de tradução para os itens não traduzidos, tendo por base o material já disponibilizado para o sítio eletrônico do PPCSA. 
Quadro 3 - Sítio Eletrônico do PPGECO

\begin{tabular}{|c|c|c|c|c|}
\hline Áreas & TF_PT & Tradução_EN & Prop. de Tradução & Prop. de Inclusão \\
\hline Cabeçalho & $\begin{array}{l}\text { Programa de Pós- } \\
\text { graduação em Ecologia } \\
\text { e Conservação dos } \\
\text { Recursos Naturais } \\
\text { UFU - Universidade } \\
\text { Federal de Uberlândia }\end{array}$ & OMITIDO & $\begin{array}{l}\text { Graduate Program in } \\
\text { Natural Resources' } \\
\text { Conservation and } \\
\text { Ecology }\end{array}$ & $\begin{array}{l}\text { Graduate Program in } \\
\text { Natural Resources } \\
\text { Conservation and } \\
\text { Ecology - Universidade } \\
\text { Federal de Uberlândia }\end{array}$ \\
\hline Rodapé & OMITIDO & NA & NA & $\begin{array}{l}\text { - UNIVERSITY } \\
\text {-GRADUATE } \\
\text { PROGRAM } \\
\text { - STUDY WITH US } \\
\text { - FURTHER } \\
\text { INFORMATION } \\
\end{array}$ \\
\hline $\begin{array}{l}\text { Menu } \\
\text { Superior } \\
\text { Horizontal }\end{array}$ & $\begin{array}{l}\text { - Buscar neste site } \\
\text { - Inglês } \\
\text { - Português } \\
\text { - Espanhol }\end{array}$ & OMITIDO & $\begin{array}{l}\text { Go to search } \\
\text { EN } \\
\text { PT } \\
\text { ES }\end{array}$ & $\begin{array}{l}\text { - Go to content } \\
\text { - Go to menu } \\
\text { - Go to footer } \\
\text { - ACCESSIBILITY } \\
\text { - HIGH CONTRAST } \\
\text { - SITE MAP } \\
\text { - FAQ } \\
\text { - CONTACT US }\end{array}$ \\
\hline \multirow{5}{*}{$\begin{array}{l}\text { Menu } \\
\text { Vertical } \\
\text { Esquerdo }\end{array}$} & O Programa & OMITIDO & & $\begin{array}{l}\text { Information about the } \\
\text { Program }\end{array}$ \\
\hline & Mestrado / Doutorado & & $\begin{array}{l}\text {-Academic Master's } \\
\text { Degree } \\
\text {-Doctor's Degree }\end{array}$ & -Doctoral Degree \\
\hline & Fale conosco & & Find Us & \\
\hline & Links Importantes & & Important Links & \\
\hline & & & & $\begin{array}{l}\text { - Research lines and } \\
\text { projects } \\
\text { - Faculty } \\
\text { - Coordination } \\
\text { - Admission process } \\
\text { - Scholarships } \\
\text { - Further information }\end{array}$ \\
\hline
\end{tabular}

Fonte: elaboração própria.

O Quadro 3 aponta as áreas da página principal do sítio eletrônico do PPGECO que poderiam estar traduzidas para o inglês, assim como no sítio eletrônico do PPCSA. O cabeçalho do sítio eletrônico não contém a tradução do nome do curso, então optou-se por propor uma tradução que fique em consonância com o sítio eletrônico do PPCSA, qual seja: Graduate Program in Natural Resources Conservation and Ecology. Observe-se que, na página inicial, o nome do programa e da universidade são traduzidos como "Graduate Program in Ecology and Conservation of Natural Resources" e "Federal University of Uberlândia", respectivamente. Sugere-se então uma padronização no uso do termo "Graduate" e que, para a manutenção da identidade da UFU, mantenha-se o nome da instituição em língua portuguesa.

O rodapé do sítio também se encontra em desacordo com o sítio do PPCSA. Foi proposta uma inclusão dos ícones em inglês traduzido, mas, para que essa inclusão possa ser efetuada, a versão em português do sítio eletrônico também precisa ser alterada para que as duas versões possuam uma similaridade de conteúdo. O rodapé poderia conter informações 
sobre a universidade, os programas de graduação, o processo de admissão e o endereço físico do curso. Inclusive, esse tipo de alteração poderá promover uma identidade visual para a UFU, com todos os programas exibindo características próximas em seus sítios eletrônicos. Embora essa identidade também possa ser vista como um "engessamento", com consequente redução do poder criativo dos web designers", o usuário poderá ter a sensação de que está acessando informações de uma mesma instituição, independentemente do programa que estiver consultando.

O menu superior horizontal também está em desacordo com o do sítio do PPCSA, pois não contém uma separação bem delimitada dos atalhos e links 'Go to content', 'Go to menu', 'Go to search' e 'Go to footer'. A inclusão desses atalhos e links em inglês precisaria vir acompanhada da inclusão dos ícones similares na versão em português. A proposta de tradução está disposta no Quadro 3.

O menu vertical na versão em português poderia conter a mesma disposição dos ícones existentes na versão em português do sítio do PPCSA. Citam-se como exemplos: a apresentação do Mestrado Acadêmico e do Doutorado separadamente; as disciplinas e as informações sobre

94 os processos seletivos para ingresso nos cursos; a oferta de Bolsas; as Normas e os Regulamentos; as Linhas de Pesquisa, os Projetos e as Publicações; os Docentes, Discentes e Técnicos; e informações institucionais sobre o programa de pós-graduação.

A seguir, apresentam-se, no Quadro 4, uma proposta de revisão do conteúdo da página inicial do PPGECO e, no Quadro 5, uma proposta de tradução da página com informações sobre o programa. Seguindo a literatura, propõem-se uma explicitação de informações culturais e uma redução de conteúdo, sobretudo no que diz respeito a legislação e informações que parecem ser pouco elucidativas ou persuasivas para o público-alvo intencionado. 
Quadro 4 - Tradução original e proposta de revisão para a página inicial do PPGECO

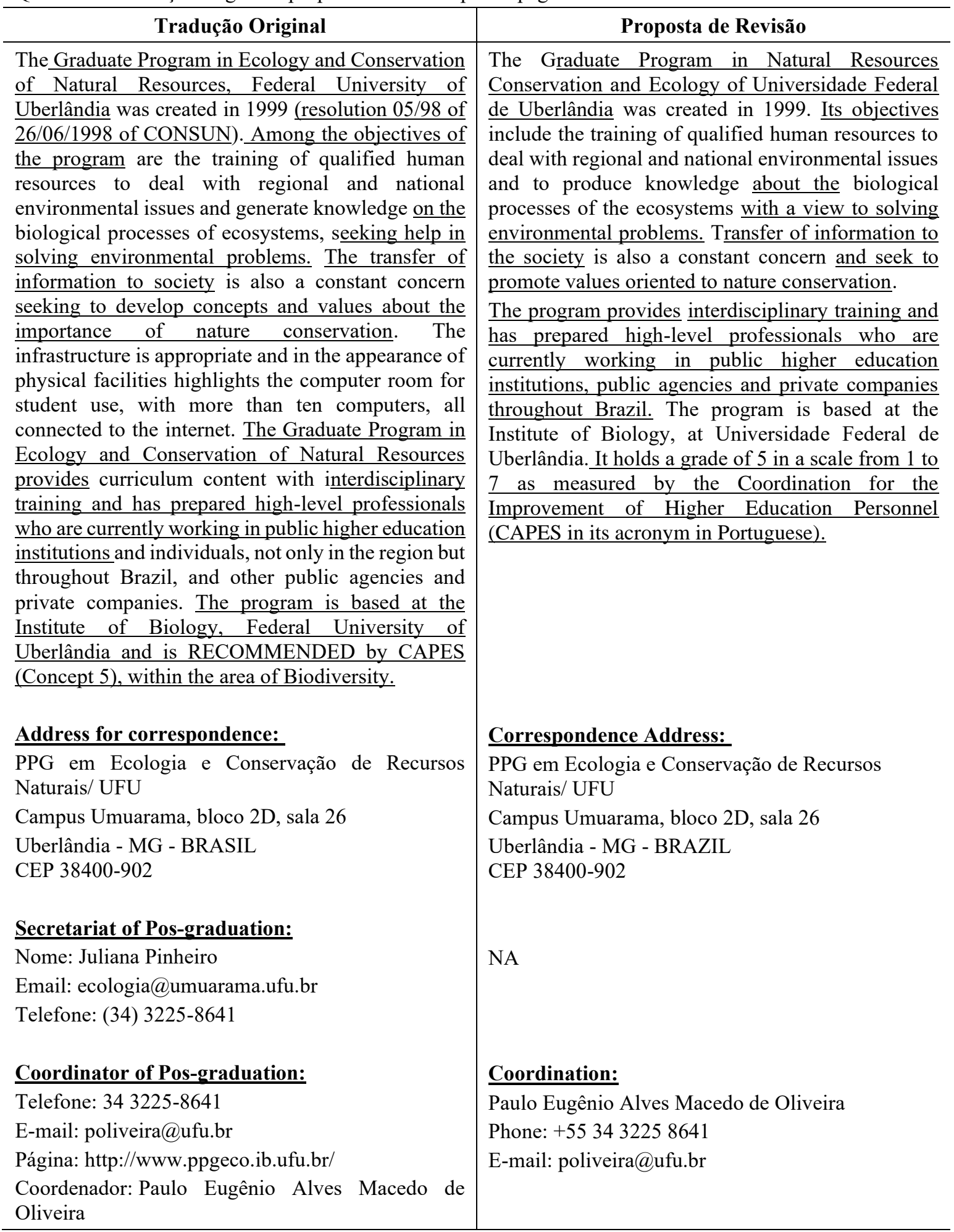

Fonte: elaboração própria.

GOIS, Helda Maria Falcão de; DA SILVA, Igor Antônio Lourenço. A tradução de dois sítios eletrônicos da Universidade Federal de Uberlândia sob o viés da internacionalização. Belas Infiéis, Brasília, v. 9, n. 4, p. 75-100, jul./set., 2020.

e-ISSN: 2316-6614. DOI: doi.org/10.26512/belasinfieis.v9.n4.2020.27494 
Quadro 5 - Texto-fonte e proposta de tradução para a página com informações sobre o PPGECO

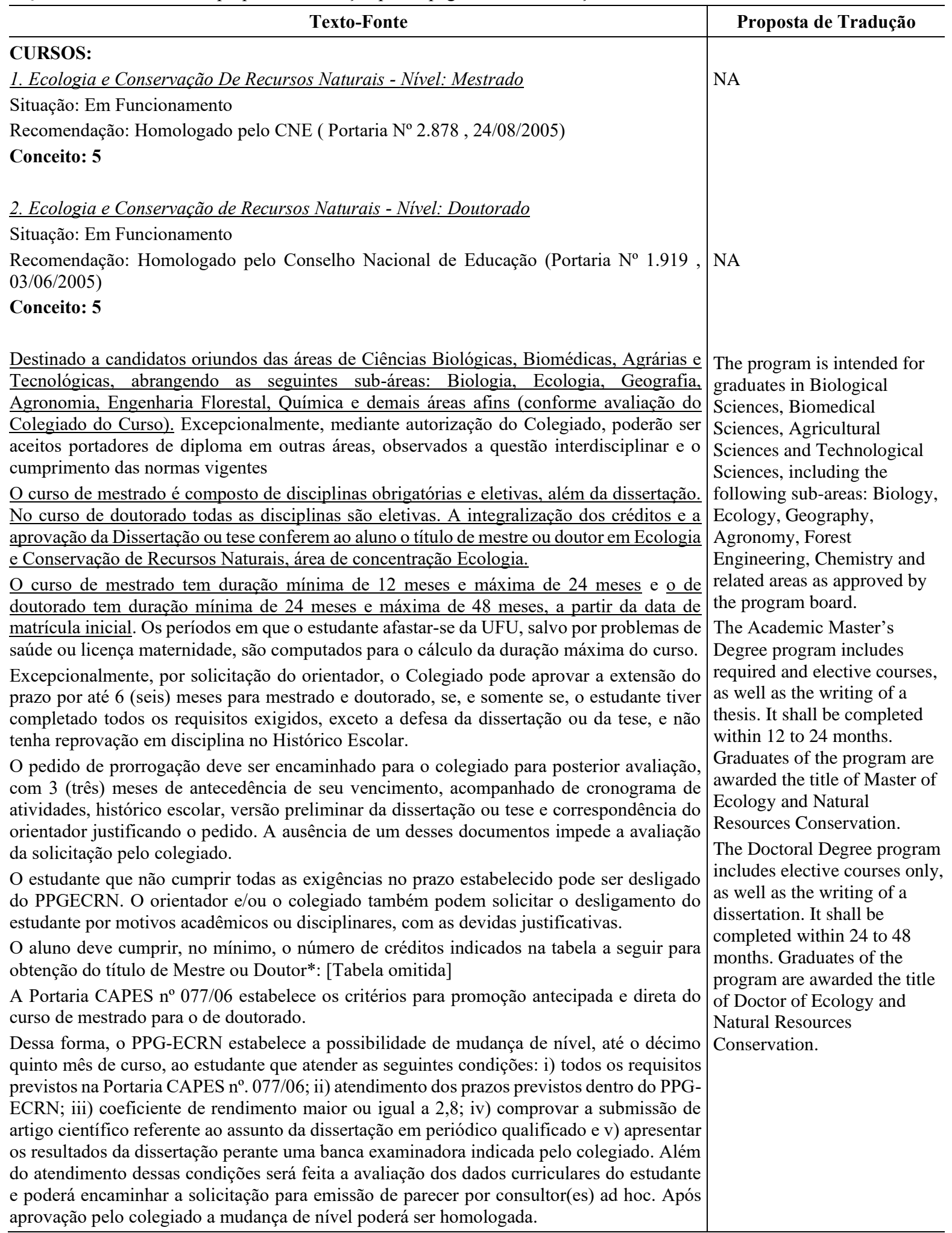
Fonte: elaboração própria.

No Quadro 4, destacaram-se em sublinhado apenas as sentenças necessárias ao entendimento do conteúdo linguístico pelo público-alvo, sendo as alterações lançadas na 
'proposta de revisão'. Por sua vez, o Quadro 5 contém uma proposta de tradução do conteúdo da página inicial do PPGECO, com as informações relevantes sobre o programa e necessárias para o público público-alvo intencionado. Os materiais linguísticos para a versão em inglês da referida página foram lançados considerando-se sempre o sítio eletrônico do PPCSA. Destacaram-se no texto-fronte, em sublinhado, apenas as frases que foram traduzidas para o inglês e inclusas na 'proposta de tradução'.

\section{Considerações Finais}

Este artigo buscou investigar o processo de internacionalização da UFU por meio dos sítios eletrônicos de dois dos seus programas de pós-graduação. Contextualizou-se o fenômeno da globalização, da internacionalização, da localização e da tradução, determinando a essência da tradução e o papel do tradutor nesse contexto. Com o aporte de Fernández-Costales (2010), observou-se que o processo de adaptação dos sítios eletrônicos universitários para outro idioma não pode ser considerado como localização, sendo o termo 'tradução de sítios universitários' mais adequado para denominar o ato comunicativo descrito nesta investigação.

Observou-se que o PPCSA e o PPGECO já iniciaram seu processo de internacionalização por meio da iniciativa de disponibilização de uma versão de seus sítios eletrônicos em língua inglesa. Ambos os sítios se configuram com caráter informacional, pois apresentam conteúdos sobre os programas, os professores, a coordenação, o processo de admissão, entre outros. Entretanto, ambos precisam ser melhorados em alguns aspectos. No caso do PPCSA, os problemas de linguagem ainda precisam ser revisados, bem como algumas questões que dificultam a compreensão do público internacional (como o processo seletivo e a nota do programa). No caso do PPGECO, o sítio praticamente não disponibiliza tradução, com texto em inglês e bastante material concorrente em português.

Algumas limitações foram encontradas no decorrer deste trabalho, pois não foi utilizado um programa de apoio à tradução ${ }^{10}$ para a extração e posterior tradução dos itens selecionados. Mesquita (2015) ressalta que o uso de ferramentas de tradução assistida por computador contribui para que o trabalho do tradutor de sítios eletrônicos seja efetuado de forma mais rápida e segura. Além disso, a falta de um glossário para o uso dos termos técnicos da UFU ou das respectivas áreas do programa foi outro problema encontrado nesta pesquisa.

Este artigo foi elaborado na tentativa de promover uma reflexão sobre um dos aspectos da internacionalização do ensino superior, qual seja, a internacionalização dos seus sítios eletrônicos. As últimas informações fornecidas pela CAPES mostram que o Brasil tem 
melhorado sua exposição no mundo globalizado do século XXI, uma melhora significativa no âmbito educacional. Contudo, como revelado na breve análise deste trabalho, ainda há muito a ser feito para aumentar a qualidade dos sítios em língua inglesa, sobretudo considerando que muitos demandam tradução especializada e, muitas vezes, são realizados como tradução inversa (i.e., da L1 para a L2) (cf. LORENZO, 1999; DA SILVA, 2019; DA SILVA et al., 2017). Também são necessários esforços para ampliar a função promocional desses sítios, principalmente no que diz respeito à divulgação do conhecimento produzido pelos programas (o que poderia estar relacionado a uma melhoria no conteúdo dinâmico, sobretudo no que diz respeito aos projetos e às pesquisas concluídas em andamento) e no que diz respeito à atração de talentos estrangeiros, seja como estudantes, professores visitantes ou mesmo docentes da instituição.

Outrossim, é preciso destacar o papel dinâmico dos sítios eletrônicos: embora o material tenha sido coletado em 2018, os mesmos problemas foram encontrados em nova consulta realizada em 07 de março de 2020. Portanto, cabe aos responsáveis pelos sítios eletrônicos compreender a relevância da constante atualização de seus conteúdos.

\section{REFERÊNCIAS}

CAPES - COORDENAÇÃO DE APERFEIÇOAMENTO DE PESSOAL DE NÍVEL SUPERIOR. A internacionalização na universidade brasileira: resultados do questionário aplicado pela CAPES (2017). Brasília: MEC, 2017. Relatório.

DA SILVA, Igor A. Lourenço. An interactional expertise-based approach to specialized inverse translation. Tradução em Revista (oniline), v. 26, p. 86-98, 2019. https://doi.org/10.17771/PUCRio.TradRev.40528

DA SILVA, Igor A. Lourenço; ALVES, Fabio; SCHMALTZ, Marcia; PAGANO, Adriana S.; WONG, Derek; CHAO, Lidia; LEAL, Ana Luísa V.; QUARESMA, Paulo; GARCIA, Caio; SILVA, Gabriel E . Translation, post-editing and directionality. In: JAKOBSEN, Arnt L.; MESA-LAO, Bartolomé (Ed.). Translation in transition: Between cognition, computing and technology. Amsterdam: John Benjamins, 2017, p. 108-134. https://doi.org/10.1075/btl.133.04lou

FERNANDEZ, Rosane Augusta. Glossário bilíngue de termos institucionais para a Universidade do Estado do Rio de Janeiro. 2011. 124 f. Dissertação (Mestrado em Linguística) - Instituto de Letras, Universidade do Estado do Rio de Janeiro, Rio de Janeiro, 2011.

FERNÁNDEZ-COSTALES, Alberto. Tradución, localización e internacionalización: el caso de las páginas web universitárias. 2010. 552 f. Tese (Doutorado em Tradução) Departamento de Filología Anglogermánica y Francesa, Universidad de Oviedo, Oviedo, 2010. 
FOUCES, Oscar Dias. Alguns elementos para uma didática da tradução de conteúdos para a internet. Revista Abehache, [s.1.], v. 1, n. 3, p. 25-50, 2016.

KUNSCH, Margarida K. Universidade e comunicação na edificação da sociedade. São Paulo: Edições Loyola, 1992.

LORENZO, María Pilar. La seguridad del traductor professional en la traducción a una lengua extranjera. In: HANSEN, G. (Ed.). Probing the process in translation: methods and results. Copenhagen Studies in Language. Copenhague: Samfundslitteratur, v. 24, p. 21-134, 1999.

MESQUITA, Leonardo Penha. Tradução comentada de um site universitário e tutorial para uso de uma ferramenta tecnológica de apoio à tradução. 2015. $80 \mathrm{f}$. Monografia de conclusão de curso (Bacharelado em Tradução) - Instituto de Letras e Linguística, Universidade Federal de Uberlândia, Uberlândia, 2015.

MIRANDA, José Antunes; STALLIVIERI, Luciane. Para uma política pública de internacionalização para o ensino superior no Brasil. Avaliação: Revista da Avaliação da Educação Superior, [s.1.], v. 22, n. 3, p. 589-613, 2017. doi: https://doi.org/10.1590/s141440772017000300002

SANDRINI, Peter. Localization and translation. MuTra Journal, [s.l.], v. 2, p. 167-191, 2008.

RAMOS, Agostinho Alberto Ferreira. O papel da tradução na comunicação institucional: O caso do IPB. 2015. 98 f. Relatório Final (Mestrado em Tradução) - Escola Superior de Educação de Bragança, Bragança, 2015.

YUNKER, John. Building a global website. Multilingual Computing: The Global Web Guide, v. 14, n. 55, p. 4-9, 2003.

\footnotetext{
${ }^{1}$ Tradução dos autores para: "La localización es el proceso de adaptar un producto de manera íntegra a una cultura de destino o locale de manera que se ajuste totalmente a los parâmetros culturales de la audiencia meta". ${ }^{2}$ Tradução dos autores para: "it refers to the business activities related to marketing a product or service in multiple regional markets".

${ }^{3}$ Tradução dos autores para: "Internationalization describes the process of enabling a product at a technical level for localization so that it can be easily adapted for a specific market after the engineering phase".

4 Tradução dos autores para: "the provision of services and technologies for the management of multilinguality across the global information flow".

5 Tradução dos autores para: "una web 'internacionalizada' es aquella que puede traducirse a un idioma de destino dado que ha sido diseñada con unos determinados parámetros y juegos de caracteres".

${ }^{6}$ Tradução dos autores para: "A website can be 'a marketing channel, a software product, a brochure, a shopping mall or all of the above', indeed a complex matter as a source text for translation".

${ }^{7}$ Tradução dos autores para: "avoid flags, this is a bad habit born out of the early days of the Web. A national flag seldom reflects a language in its entirety: what kind of flag would you use for Spanish? Argentina, Spain, Mexico, Guatemala or even the US [...]?"

${ }^{8}$ Tradução dos autores para: “A Coordenação de Aperfeiçoamento de Pessoal de Nível Superior (Capes), fundação do Ministério da Educação (MEC), desempenha papel fundamental na expansão e consolidação da pós-graduação stricto sensu (mestrado e doutorado) em todos os estados da Federação." (Disponível em: http://www.capes.gov.br/. Acesso em: 2 mar. 2020.)

${ }^{9}$ Tradução dos autores para: "Os conceitos CAPES seguem escalas de 01 ao 07, sendo que 1 e 2 descredenciam o programa; 3 significa desempenho regular atendendo ao padrão mínimo de qualidade; 4 é considerado um bom
}

GOIS, Helda Maria Falcão de; DA SILVA, Igor Antônio Lourenço. A tradução de dois sítios eletrônicos da Universidade Federal de Uberlândia sob o viés da internacionalização. Belas Infiéis, Brasília, v. 9, n. 4, p. 75-100, jul./set., 2020.

e-ISSN: 2316-6614. DOI: doi.org/10.26512/belasinfieis.v9.n4.2020.27494 
desempenho; 5 é a nota máxima para programas com apenas mestrado; conceitos 6 e 7 indicam desempenho equivalente a alto padrão internacional.” (Disponível em: http://www.capes.gov.br/. Acesso em: 2 mar. 2020.)

${ }^{10}$ Todo "PAT [programa de apoio à tradução] mostra o texto de partida na tela, com um espaço para a tradução, abaixo ou ao lado. A medida que traduzimos, vamos vendo o texto de partida par a par com o de chegada. Isso, em si, já facilita muito o trabalho do tradutor.” (NOGUEIRA, D.; NOGUEIRA, V., 2004, p. 19)

\section{NOTA DOS AUTORES}

Helda Maria Falcão de GOIS - Mestranda em Estudos Linguísticos pela Universidade Federal de Uberlândia. Bacharel em Tradução (2018) pela mesma instituição. Universidade Federal de Uberlândia, Instituto de Letras e Linguística, Programa de Pós-Graduação em Estudos Linguísticos. Uberlândia, Minas Gerais, Brasil.

ORCID: https://orcid.org/0000-0002-3919-1268

Currículo acadêmico: http://lattes.cnpq.br/2008200274809453

E-mail: heldafgois@hotmail.com

Igor A. Lourenço DA SILVA - Professor adjunto na Universidade Federal de Uberlândia. Membro permanente dos Programas de Pós-graduação em Estudos Linguísticos da Universidade Federal de Minas Gerais (POSLIN) e da Universidade Federal de Uberlândia (PPGEL). Doutor (2012) e Mestre (2007) em Estudos Linguísticos pela Universidade Federal de Minas Gerais. Licenciado (2004) e Bacharel (2003) em Letras - Inglês pela mesma instituição. Universidade Federal de Uberlândia, Instituto de Letras e Linguística, Bacharelado em Tradução. Uberlândia, Minas Gerais, Brasil.

ORCID: https://orcid.org/0000-0003-0738-3262

Currículo acadêmico: http://lattes.cnpq.br/6440150670404908

E-mail: ials@ufu.br, ialsigor@gmail.com 